\title{
Vencemos mais uma etapa, conseguimos a indexação na base de dados SciELO
}

\author{
One more stage was overcome; we have obtained SciELO's database indexation
}

No dia 9 de novembro de 2009 realizou-se na BIREME/OPAS/OMS, São Paulo, a Reunião do Comitê de Avaliação e Seleção de Periódicos LILACS Brasil, a última etapa do processo de seleção de periódicos para a base de dados LILACS, e como resultado final da análise de conteúdo, a Revista Dor Pesquisa, Clínica e Terapêutica (Revista Dor) foi aprovada mediante a implantação das recomendações de normalização e recomendações do Comitê. Para a indexação definitiva da Revista Dor na base de dados LILACS, entretanto, foi necessário cumprir uma série de exigências, de modo que isso realmente aconteceu em 01 de setembro de 2010. Por outro lado, houve a recomendação para aumentar a abrangência de autores dos artigos de outros estados, visto que a maioria (acima de 60\%) era do Estado de São Paulo.

Gostaria de salientar que essa Diretoria objetiva engrandecer a área de atuação em clínica de dor solidificando e discutindo nosso portfólio científico, agregando valores a esse processo através da experiência dos que nos antecederam e analisando de modo continuado os nossos objetivos e resultados. Isso acaba por criar um perfil de seriedade diante da comunidade científica. Não poderia deixar de citar o investimento persistente e competente do nosso Editor chefe - Prof. Irimar de Paula Posso, cuja trajetória no meio acadêmico e associativo dispensa comentários. E como todo trabalho tem resultado, em 21 de janeiro de 2011 recebemos a informação de que a Revista Dor havia sido aprovada na primeira etapa do processo de seleção e avaliação de periódicos da coleção SciELO Brasil e, que seria submetida à análise de conteúdo científico, realizada por 3 especialistas da sua respectiva área temática. Finalmente, em reunião realizada em 8 de abril de 2011 o Comitê Consultivo, concedeu parecer favorável com restrições ao ingresso da Revista Dor na SciELO Brasil.

Desse modo, a Revista Dor na coleção SciELO Brasil e seu desempenho será acompanhado pelos membros do Comitê Consultivo anualmente e as restrições identificadas na análise de formato e endogenia, bem como os comentários dos revisores ad hoc e dos membros do Comitê Consultivo para a melhoria do periódico, foram apresentados no parecer e deverão ser atendidos no prazo máximo de um ano.

As restrições a serem atendidas nesse período são: 1) aumento do número de autores dos artigos de outros estados brasileiros; 2) aumento do número de artigos publicados por ano, atendendo à quantidade mínima exigida pelos Critérios SciELO Brasil; 3) aprimoramento da qualidade dos artigos de revisão, em especial na abrangência às bases de dados consultadas.

Apesar de nossa disposição para que a Revista Dor: Pesquisa Clínica e Terapêutica atenda as restrições e tenha um crescimento sustentado, sem a sua ajuda não será possível manter a nossa indexação LILACS e SciELO; portanto é imprescindível a sua cooperação, enviando artigos de qualidade, principalmente de artigos originais, pois um dos requisitos a serem respeitados, é a publicação em cada edição de mais de 50\% de artigos originais. Também são necessários artigos de revisão e de atualização, bem como de relatos de caso de nível elevado, pois o número mínimo de artigos por edição deve ser 17 a 18.

Assim, essas medidas são necessárias e prioritárias para divulgação e manutenção da nossa indexação LILACS e SciELO, além de ser o alicerce para a criação de futura etapa desse processo que é a indexação na MEDLINE. Com isso, abriremos a porta para o mundo, mostrando que também trabalhamos com seriedade e podemos estabelecer referencial teórico.

Avante!

Prof. Dr. Durval Campos Kraychete Diretor Científico da Sociedade Brasileira para o Estudo da Dor 